\title{
Self-reported contacts for mental health problems by rural residents: predicted service needs, facilitators and barriers
}

Tonelle E Handley ${ }^{1,2,3^{*}}$, Frances J Kay-Lambkin ${ }^{1,3}$, Kerry J Inder ${ }^{1,4}$, Terry J Lewin ${ }^{1}$, John R Attia ${ }^{4,5}$, Jeffrey Fuller ${ }^{6}$, David Perkins ${ }^{2}$, Clare Coleman ${ }^{2}$, Natasha Weaver ${ }^{4,5}$ and Brian J Kelly ${ }^{1}$

\begin{abstract}
Background: Rural and remote Australians face a range of barriers to mental health care, potentially limiting the extent to which current services and support networks may provide assistance. This paper examines self-reported mental health problems and contacts during the last 12 months, and explores cross-sectional associations between potential facilitators/barriers and professional and non-professional help-seeking, while taking into account expected associations with socio-demographic and health-related factors.
\end{abstract}

Methods: During the 3-year follow-up of the Australian Rural Mental Health Study (ARMHS) a self-report survey was completed by adult rural residents ( $N=1,231 ; 61 \%$ female; $77 \%$ married; $22 \%$ remote location; mean age $=59$ years), which examined socio-demographic characteristics, current health status factors, predicted service needs, self-reported professional and non-professional contacts for mental health problems in the last 12 months, other aspects of help-seeking, and perceived barriers.

Results: Professional contacts for mental health problems were reported by $18 \%$ of the sample (including 14\% reporting General Practitioner contacts), while non-professional contacts were reported by 16\% (including 14\% reporting discussions with family/friends). Perceived barriers to health care fell under the domains of structural (e.g., costs, distance), attitudinal (e.g., stigma concerns, confidentiality), and time commitments. Participants with 12-month mental health problems who reported their needs as met had the highest levels of service use. Hierarchical logistic regressions revealed a dose-response relationship between the level of predicted need and the likelihood of reporting professional and non-professional contacts, together with associations with socio-demographic characteristics (e.g., gender, relationships, and financial circumstances), suicidal ideation, and attitudinal factors, but not geographical remoteness.

Conclusions: Rates of self-reported mental health problems were consistent with baseline findings, including higher rural contact rates with General Practitioners. Structural barriers displayed mixed associations with help-seeking, while attitudinal barriers were consistently associated with lower service contacts. Developing appropriate interventions that address perceptions of mental illness and attitudes towards help-seeking is likely to be vital in optimising treatment access and mental health outcomes in rural areas.

Keywords: Rural, Mental health, Service utilisation, Treatment barriers, Attitudes

\footnotetext{
*Correspondence: Tonelle.Handley@newcastle.edu.au

${ }^{1}$ Centre for Translational Neuroscience and Mental Health, University of

Newcastle and Hunter New England Health, Callaghan, NSW, Australia

${ }^{2}$ Centre for Rural and Remote Mental Health, University of Newcastle,

Orange, NSW, Australia

Full list of author information is available at the end of the article
} 


\section{Background}

International evidence suggests that the prevalence of mental health $(\mathrm{MH})$ problems is similar across rural and urban areas [1,2]. In Australia, although mental illness may occur at similar rates across geographical regions $[3,4]$, rural areas generally witness considerably lower $\mathrm{MH}$ service use [5,6]. Distance to services is among the most significant issues [7], with longer travelling time to MH services associated with clients making fewer visits, and being less likely to receive care in adherence with treatment guidelines [8]. The shortage of local services (especially specialist services) also contributes to longer waiting periods, which has been identified by rural General Practitioners (GP) as a referral deterrent [9]. Residing a greater distance from urban centres is associated with fewer community health centre contacts, outpatient services and days spent in inpatient wards [10].

Previous research has found that even where $\mathrm{MH}$ services are available, people residing in rural areas display lower help-seeking $[6,11]$. This may be due to attitudes which value self-reliance and a preference for self-management of $\mathrm{MH}$ problems, as well as higher stigma in rural areas [11,12]. In fact, perceived stigma may be more central in determining $\mathrm{MH}$ service use than even the severity of the condition or the level of disability $[13,14]$. Conversely, positive attitudes towards help-seeking, and believing that a GP would be helpful for $\mathrm{MH}$ concerns, are significantly associated with lifetime GP consultations by rural residents, after controlling for current psychological distress [15]. Confidentiality is also an important issue, with rural residents expressing concerns that their personal information may be disclosed, or that other residents will see them attending healthcare services [16].

There is some evidence that negative attitudes about treatment effectiveness are higher in more remote areas of Australia [17] and mixed evidence about the contribution of perceived stigma towards mental illness $[13,15,18]$. Simultaneously, increasing remoteness is typically associated with greater difficulties accessing services [19] and potentially greater reliance on internetderived information [20]. Due to potential correlations between these distinct "barriers types" (i.e., attitudinal, physical/structural barriers), it is necessary to examine both constructs in order to establish their relative impact in relation to help-seeking. This has been explored previously, with findings indicating a greater influence of attitudinal than structural barriers [21-23]. However, past research has generally focused on urban populations, which may differ in their patterns of structural and attitudinal barriers. Understanding the relative contributions of different barriers to rural $\mathrm{MH}$ service use is vital to ensure that efforts to optimise service use are appropriately directed.
Our earlier report from the Australian Rural Mental Health Study (ARMHS) examined baseline cross-sectional associations between socio-demographic, current health status, and service utilization variables [24]; however, at that time, limited data had been collected about service use barriers. The observed baseline rate of professional contacts for $\mathrm{MH}$ problems during the previous 12 months exceeded the national rate (17\% vs. $11.9 \%)$ [25]. This was primarily due to higher rural contact rates with GPs (12\% vs. 8.1\%), which may largely reflect the older age of the ARMHS sample. Selected data from the ARMHS 3-year follow-up have also been examined [26] to try to better understand the feasibility of using internet-delivered MH treatments among rural populations, together with relevant barriers (e.g., internet availability, treatment acceptability, previous exposure).

The current analysis of the ARMHS 3-year follow-up data is a more comprehensive exploration of perceived barriers to $\mathrm{MH}$ care in rural areas, and their cross-sectional associations with professional and non-professional helpseeking. Importantly, this analysis seeks to account for the influence of socio-demographic factors, including geographical remoteness, and current health status factors, thereby enabling a more thorough exploration of the role of perceived structural, attitudinal and other barriers. In short, the primary questions of interest for this paper are: 1) who self-reports current $\mathrm{MH}$ problems and associated help-seeking; 2) what potential facilitators/barriers can be identified; and 3) how much of a contribution do these facilitators/barriers make to reported professional and non-professional help-seeking, after taking into account the influence of more traditional indicators (e.g., sociodemographic, location, and health related factors). In broad terms, it was hypothesised that there would be a dose-response relationship between predicted service needs and reported rates of service use (i.e., higher service usage among those with higher severity of problems) and that perceived barriers, particularly attitudinal barriers, would be associated with lower reported service usage.

\section{Methods}

\section{Study sample}

Participants included in the current analysis completed the third phase (3-year follow-up) of the ARMHS project, a longitudinal investigation of $\mathrm{MH}$ in rural and remote New South Wales (NSW). Baseline data collection began in May 2007, with follow-ups conducted at 1-, 3- and 5years post-baseline; the 3-year follow-up was conducted from February 2011 to March 2012. Residents of nonmetropolitan areas were selected randomly from the Electoral Roll, with recruitment covering four Australian Standard Geographical Classification (ASGC) categories: inner regional, outer regional, remote, and very remote. Deliberate over-sampling from remote and very remote 
regions was undertaken to ensure sufficient representation from these areas. See Kelly et al. [27,28] for full descriptions of the ARMHS project and sampling methods.

Written informed consent was obtained from each participant with the return of their baseline postal survey. Ethical approval was obtained from the Human Research Ethics Committees of the Universities of Newcastle and Sydney, and the Greater Western, Hunter New England and North Coast Area Health Services.

\section{Measures}

\section{Participant characteristics}

Socio-demographic items included questions about age, gender, marital status, and commitments, including regular employment, living with children, and caring for a disabled or ill family member/friend. Perceived financial circumstances was rated on a 6-point scale from 'prosperous' to 'very poor', adapted from the Household, Income and Labour Dynamics in Australia (HILDA) Survey [29].

\section{Predicted need for $\mathrm{MH}$ services}

Each individual's likely current need for professional $\mathrm{MH}$ services was quantified using the Predicted Service Need Index (PSNI). The PSNI was initially developed using baseline ARMHS survey data [as detailed in 24], with the integrity of the scoring algorithms re-confirmed using 3-year survey data; see Additional file 1 for further details. Overall scores on the PSNI range from 0 to 14 , obtained by summing the integer weights (from 0 to 3 ) assigned to 16 categories across seven health status measures: overall ratings of mental and physical health; Kessler-10 (K10) [2,30]: current psychological distress; Alcohol Use Disorders Identification Test (AUDIT) [31,32]: current hazardous alcohol use; Patient Health Questionnaire-9 (PHQ-9) [33]: current depressive symptoms; recent adverse life events; and current smoking status. In addition to its use as a continuous measure (with higher scores reflecting an increased likelihood or predicted need for professional services), three PSNI categories have also been identified: low (0-1); medium (2-5); and high (>5) estimated need; see earlier report [24] and Additional file 1 for further details.

\section{Suicidal ideation}

An independent measure of suicidal ideation was also included; item 9 of the PHQ-9 asks respondents to rate the frequency of "thoughts that you would be better off dead, or of hurting yourself in some way" during the past two weeks; responses were dichotomised into a 'yes/no' variable.

\section{$\mathrm{MH}$ problems, contacts and barriers}

The trigger question for the section of the 3-year follow-up survey enquiring about recent $\mathrm{MH}$ problems and contacts was: "In the past 12 months have you experienced any mental health problems such as stress, anxiety or depression or worries about alcohol or drugs?" Thereafter, participants with a positive response to this question were asked several questions regarding their help-seeking during the previous 12-months, including: a) whether they had sought any help or advice for $\mathrm{MH}$ problems; b) where they sought help (and how many times); c) the type of help received (e.g., information about $\mathrm{MH}$, medication); and $\mathrm{d}$ ) whether they felt they had received as much help as needed. For the 3-year follow-up, a scannable booklet was used, necessitating some changes to the response options and layout (relative to earlier phases). The combined questions about sources and frequency of contacts included 11 professional sources (e.g., GP, psychiatrist, psychologist, $\mathrm{MH}$ nurse, Lifeline, specialist doctor), and 4 nonprofessional sources (e.g., family/friends, alternative therapist, clergy). Seven response options were provided for the frequency of contacts in the last 12 months with each source, ranging from 'None', '1-2 times', to '13+ times', which were assigned weights of $0,2,4,6,9,12$, and 18 contacts respectively.

Participants with self-identified $\mathrm{MH}$ problems during the last 12 months who either: a) did not seek help; or b) sought help, but did not receive as much as needed, completed additional questions about perceived barriers to $\mathrm{MH}$ treatment. Twelve potential barriers were rated on 5-point scales (ranging from 'not at all' to 'a lot'), covering issues such as treatment costs, distance to services, and views on treatment usefulness. For participants who endorsed the specific barrier "I prefer to manage myself," additional questions enquired as to the main reason for this. Guided by findings from a preliminary series of principal component analyses (see Additional file 1), scores on three perceived barriers to $\mathrm{MH}$ treatment factors were obtained by averaging responses to the allocated items (producing scores ranging from 1 to 5 for each factor): Factor 1, 'Structural barriers to helpseeking' (5 items, e.g., "It is too far to travel"); Factor 2, 'Attitudinal barriers to help-seeking' (4 items, e.g., "I didn't think anything could help"); and Factor 3, 'Time commitments' ( 2 items, e.g., "I am too busy caring for someone else"); see Additional file 1: Table S3 for item content and factor assignments.

\section{Feasibility of internet-delivered $\mathrm{MH}$ services}

Participants completed two questions that were used to determine whether internet-delivered $\mathrm{MH}$ treatments would be a feasible option for them: about their attitudes ("would you consider using the computer or the internet as a way of accessing treatment for your mental health?"); and internet access (dialup, ADSL, or broadband) in their home or elsewhere. 


\section{Data analysis}

Data were analysed using the Statistical Package for Social Sciences (SPSS version 20; Chicago, IL, USA). For overall univariate comparisons between sub-groups, simple chi-square tests (for categorical variables) or one-way ANOVAs (for continuous variables) were used, or alternatively ANCOVAs, when statistically controlling for the influence of other factors. Hierarchical logistic regressions were used in the major analyses examining relationships between potential facilitators/barriers and self-reported contacts for $\mathrm{MH}$ problems; Adjusted Odds Ratios (AORs) are reported, together with associated 99\% Confidence Intervals (CI). The threshold for statistical significance was set at $p<.01$ for all analyses.

\section{Results}

\section{Sub-groups and basic socio-demographic characteristics}

There were 1,266 respondents to the ARMHS 3-year follow-up (48\% of baseline respondents or $69 \%$ of those who completed at least one of the three follow-up phases), 35 of whom were excluded from the current analyses (i.e., 15 now residing in a metropolitan area and 20 with insufficient $\mathrm{MH}$ data). Among the 1,231 respondents with relevant data, 394 (32.0\%) reported experiencing a $\mathrm{MH}$ problem in the last 12 months. Within this subsample, 143 (36.3\%) indicated that they had not sought any help or advice, $176(44.7 \%)$ reported that they had sought and received as much help as needed, and 75 (19.0\%) reported receiving insufficient help. The upper portion of Table 1 presents the socio-demographic characteristics of these sub-groups.

As evidenced by the statistically significant comparisons in Table 1, on average, respondents with a self-reported 12-month $\mathrm{MH}$ problem were younger (55.01 vs. 60.70 years), more likely to have completed high school or above (76\% vs. 67\%), less likely to be married (69\% vs. 81\%), and more likely to be experiencing financial problems (35\% vs. 27\%). Within this sub-sample, the proportion of females was higher among those who had sought help, particularly those reporting unmet needs ( $80 \%$ female). The latter sub-group were also more likely to report financial problems (52\% vs. 31\%).

\section{Predicted service needs and potential facilitators/barriers}

Respondents to the ARMHS 3-year survey had similar PSNI profiles to those assessed at baseline [24], namely: $67 \%$ low (0-1); 24\% medium (2-5); and 9\% high $(>5)$ estimated current need for professional $\mathrm{MH}$ services. As detailed in the lower portion of Table 1, respondents with a self-reported 12-month $\mathrm{MH}$ problem had substantially higher mean PSNI scores (aggregate $=3.51 \mathrm{vs}$. 0.89), particularly those reporting unmet needs, whose mean score (of 4.81) was close to our threshold for 'high predicted service need'.
The other characteristics in Table 1 were viewed as potential facilitators of and/or barriers to help-seeking, depending on your level of service need. So, for example, three-quarters $(76 \%)$ of the sub-group with a 12-month $\mathrm{MH}$ problem who had not sought any help were currently employed or involved in volunteer work, which could have simultaneously reduced their available time for help-seeking and increased their capacity to access services (e.g., through work related connections or a better financial position). This sub-group also tended to have lower rates of suicidal ideation during the last two-weeks, relative to those seeking help (4.9\% vs. $11.2 \%, p=.023$ ).

As expected, those without a 12-month $\mathrm{MH}$ problem reported the lowest suicidal ideation $(1.1 \%$ vs. $8.9 \%$ for the other three sub-groups) and they also reported the lowest preparedness to use the internet for $\mathrm{MH}$ treatment/information ( $21 \%$ vs. $50 \%$ ), which may reflect their low current need. The remaining statistically significant associations in Table 1, showing that those without a 12month $\mathrm{MH}$ problem had a lower likelihood of being employed or having children in the house, may simply reflect the age differentials noted earlier.

\section{Help-seeking patterns}

At the 3-year follow-up, the overall rate of self-reported professional contacts for $\mathrm{MH}$ problems during the last 12 months was $18 \%$ (216 of 1,231), including 14\% (170) reporting GP contacts. Non-professional contacts were reported by $16 \%$ (192), including $14 \%$ (173) reporting discussions with family/friends. Telephone or internet contacts for $\mathrm{MH}$ problems were also reported by $2.7 \%$ (33) of participants, most of whom (29, or $88 \%$ ) also reported professional contacts. Consequently, in total, one-fifth of participants (251 of 1,231, or 20\%) reported at least one contact for $\mathrm{MH}$ problems during the last 12 months.

As shown in Table 2, among the two sub-groups who actually reported seeking help, there were comparable patterns (i.e., no significant sub-group differences) with respect to the likelihood of having 'any contacts' and the estimated number of contacts (by users). Among those reporting any contacts $(\mathrm{N}=251)$, the mean number was 15.15 contacts $(S D=16.45$; median $=10$; range: 2 to 132 ) during the preceding 12 months.

The most common type of help provided was medication (47.0\%), followed by counselling (37.5\%), general $\mathrm{MH}$ information (29.1\%), or help with a specific aspect of their life (21.5\%), such as housing, money, or work. Comparisons between the sub-groups whose needs were met versus not met revealed similar profiles for the type of help provided: medication (50.0\% vs. 40.0\%, $p=.146$ ); counselling (39.8\% vs. 32.0\%, $p=.244)$; general $\mathrm{MH}$ information $(29.0 \% v s .29 .3 \%, p=.955)$; and help with a specific aspect of their life (22.2\% vs. $20.0 \%, p=.703)$. 
Table 1 Characteristics of Australian Rural Mental Health Study (ARMHS) participants at 3-year follow-up

\begin{tabular}{|c|c|c|c|c|c|c|c|}
\hline \multirow[t]{3}{*}{ Characteristic } & \multirow[t]{3}{*}{$\begin{array}{l}\text { Total sample } \\
(\mathrm{N}=1231)\end{array}$} & \multirow[t]{3}{*}{$\begin{array}{l}\text { No } \mathrm{MH} \text { problems } \\
\text { in last } 12 \text { months } \\
(\mathrm{N}=837)\end{array}$} & \multicolumn{3}{|c|}{$\begin{array}{l}\text { Self-reported MH } \\
\text { problems in last } \\
12 \text { months }(\mathrm{N}=394)\end{array}$} & \multicolumn{2}{|c|}{$\begin{array}{l}\text { Statistical comparisons } \\
\text { (p-values) }\end{array}$} \\
\hline & & & \multirow{2}{*}{$\begin{array}{l}\text { Help/advice } \\
\text { not sought } \\
(\mathrm{N}=143)\end{array}$} & \multicolumn{2}{|l|}{$\begin{array}{l}\text { Help/advice } \\
\text { sought }\end{array}$} & \multirow[t]{2}{*}{$\begin{array}{l}\text { No vs. Any } \mathrm{MH} \\
\text { problems }(\mathrm{df}=1)\end{array}$} & \multirow{2}{*}{$\begin{array}{l}\text { Between help/ } \\
\text { advice categories } \\
(\mathrm{df}=2 \text { ) }\end{array}$} \\
\hline & & & & $\begin{array}{l}\text { Needs met } \\
(N=176)\end{array}$ & $\begin{array}{l}\text { Needs not } \\
\text { met }(\mathrm{N}=75)\end{array}$ & & \\
\hline \multicolumn{8}{|c|}{ Socio-demographic variables: } \\
\hline Age (mean, SD) & $58.87(13.27)$ & $60.70(12.95)$ & $53.54(13.12)$ & $55.85(13.10)$ & $55.87(12.12)$ & $* *$ & .243 \\
\hline Gender: female $(n, \%)$ & $753(61)$ & $494(59)$ & $80(56)$ & $119(68)$ & $60(80)$ & .024 & ** \\
\hline $\begin{array}{l}\text { Education: high } \\
\text { school or above }(n, \%)\end{array}$ & $857(70)$ & $559(67)$ & $108(76)$ & $138(78)$ & $52(69)$ & $.002^{*}$ & .309 \\
\hline $\begin{array}{l}\text { Marital status: } \\
\text { married/defacto }(n, \%)\end{array}$ & $950(77)$ & $679(81)$ & $103(72)$ & $126(72)$ & $42(56)$ & $* *$ & .029 \\
\hline $\begin{array}{l}\text { Remoteness (ASGC) } \\
\text { category: remote/very } \\
\text { remote }(n, \%)\end{array}$ & $268(22)$ & $185(22)$ & $26(18)$ & $41(23)$ & $16(21)$ & .681 & .537 \\
\hline $\begin{array}{l}\text { Financial position: } \\
\text { Just getting along } \\
\text { to very poor }(n, \%)\end{array}$ & $362(29)$ & $224(27)$ & $43(30)$ & $56(32)$ & $39(52)$ & $.003^{*}$ & $.003^{*}$ \\
\hline \multicolumn{8}{|l|}{ Potential facilitators/barriers: } \\
\hline $\begin{array}{l}\text { Employed or } \\
\text { volunteer work }(n, \%)\end{array}$ & $700(57)$ & $446(53)$ & $109(76)$ & $104(59)$ & $41(55)$ & $* *$ & ** \\
\hline $\begin{array}{l}\text { Children in house } \\
(n, \%)\end{array}$ & $309(25)$ & $183(22)$ & $51(36)$ & $53(30)$ & $22(29)$ & $* *$ & .493 \\
\hline $\begin{array}{l}\text { Caring for family } \\
\text { member/friend }(n, \%)\end{array}$ & $129(11)$ & $83(9.9)$ & $12(8.4)$ & $22(13)$ & $12(16)$ & .347 & .226 \\
\hline $\begin{array}{l}\text { Predicted Service } \\
\text { Need Index (mean, SD) }\end{array}$ & $1.73(2.53)$ & 0.89 (1.54) & $3.01(2.86)$ & 3.35 (3.11) & 4.81 (3.76) & $* *$ & $* *$ \\
\hline $\begin{array}{l}\text { Suicidal ideation-last } \\
\text { two-weeks }(n, \%)\end{array}$ & $44(3.6)$ & $9(1.1)$ & $7(4.9)$ & $16(9.1)$ & $12(16)$ & $* *$ & .023 \\
\hline $\begin{array}{l}\text { Easy access to } \\
\text { internet }(n, \%)\end{array}$ & 941 (76) & $628(75)$ & $116(81)$ & $144(82)$ & $53(71)$ & .089 & .111 \\
\hline $\begin{array}{l}\text { Would use internet } \\
\text { for MH treatment/ } \\
\text { information }(n, \%)\end{array}$ & $372(30)$ & $175(21)$ & $62(43)$ & $100(57)$ & $35(47)$ & $* *$ & .047 \\
\hline
\end{tabular}

Note: Separate statistical comparisons were made: 1) between those with and without self-reported mental health (MH) problems in the last 12 months; and 2) between the three help/advice categories (i.e., among those reporting problems: help/advice not sought; sought-needs met; or sought-needs not met); using either chi-square tests (for categorical variables) or one-way ANOVAs (for continuous variables): ${ }^{*} p<0.01 ;{ }^{* *} p<0.001$.

\section{Perceived barriers to adequate health care: dimensions and profiles}

The three barriers dimensions that were identified (i.e., structural, attitudinal, and time commitments) provided a convenient way of representing participants' perceptions. Nevertheless, amongst those to whom the barriers questions were addressed $(\mathrm{N}=218)$, mean endorsement ratings were generally low ( $<2.4$ on the $1-5$ scale), although half $(53.7 \%)$ identified some structural barriers and most (93.1\%) identified some attitudinal barriers (i.e., at least one item rated above 'not at all').

As shown in Table 3, the sub-group reporting that their $\mathrm{MH}$ care needs were not met were more likely to have identified structural barriers as reasons that stopped or delayed their ability to get help. They also tended to report time commitments $(p=.027)$ among their reasons for not receiving help. These comparisons were based on ANCOVAs controlling for socio-demographic differences; however, it is worth noting that across these sub-groups financial position was strongly associated with the identification of structural barriers (mean for 'just getting along to very poor': $2.06 v s .1 .39$ for others, $p<.001$ ).

One of the components of attitudinal barriers (a preference for self-management) was further explored in the survey. As shown in the lower portion of Table 3, among those who did not seek help, the main reasons endorsed for self-management were feelings of discomfort talking about problems (35.6\%) and reliance on family/friends 
Table 2 Self-reported professional, non-professional and telephone/internet contacts during the last 12 months for MH problems

\begin{tabular}{|c|c|c|c|c|c|c|c|c|}
\hline \multirow[t]{3}{*}{ Contact type } & \multicolumn{6}{|c|}{ Sought help/advice for MH problems in last 12 months } & \multirow{2}{*}{\multicolumn{2}{|c|}{$\begin{array}{l}\text { Statistical comparisons } \\
\text { (p-values) }\end{array}$}} \\
\hline & \multicolumn{2}{|c|}{ Total sub-sample $(\mathrm{N}=251)$} & \multicolumn{2}{|c|}{ Needs met $(\mathrm{N}=176)$} & \multicolumn{2}{|c|}{ Needs not met $(\mathrm{N}=75)$} & & \\
\hline & $\begin{array}{l}\text { Any contacts } \\
\mathrm{N}(\%)\end{array}$ & $\begin{array}{l}\text { Number of } \\
\text { contacts }^{*} \\
\text { mean (SD) }\end{array}$ & $\begin{array}{l}\text { Any contacts } \\
\mathrm{N}(\%)\end{array}$ & $\begin{array}{l}\text { Number of } \\
\text { contacts }^{*} \\
\text { mean (SD) }\end{array}$ & $\begin{array}{l}\text { Any contacts } \\
\mathrm{N}(\%)\end{array}$ & $\begin{array}{l}\text { Number of } \\
\text { contacts }^{*} \\
\text { mean (SD) }\end{array}$ & Any contacts & $\begin{array}{l}\text { Number of } \\
\text { contacts }^{*}\end{array}$ \\
\hline All professional contacts & $216(86)$ & $10.35(14.20)$ & $154(88)$ & $11.03(15.84)$ & $62(83)$ & $8.66(8.77)$ & .312 & .269 \\
\hline General practitioner (GP) & $170(68)$ & $4.32(3.83)$ & $122(69)$ & $4.31(3.82)$ & $48(64)$ & $4.35(3.89)$ & .409 & 948 \\
\hline All non-professional contacts & $192(77)$ & $7.48(6.76)$ & $141(80)$ & $7.09(6.15)$ & $51(68)$ & $8.57(8.19)$ & .038 & .180 \\
\hline Friend or family & $173(69)$ & $6.26(5.33)$ & $128(73)$ & $5.81(4.84)$ & $45(60)$ & $7.53(6.41)$ & .046 & .062 \\
\hline $\begin{array}{l}\text { Telephone or internet } \\
\text { contacts (e.g., Lifeline) }\end{array}$ & $33(13)$ & $3.52(2.06)$ & $27(15)$ & $3.33(1.47)$ & $6(8)$ & $4.33(3.88)$ & .115 & .290 \\
\hline All contacts & $251(100)$ & 15.15 (16.45) & $176(100)$ & $15.84(17.75)$ & 75 (100) & $13.51(12.82)$ & - & .309 \\
\hline
\end{tabular}

Note: Statistical comparisons between the sub-groups were based on chi-square tests (for categorical variables) or one-way ANOVAs (for continuous variables): ${ }^{*} \mathrm{p}<0.01 ;{ }^{* *} \mathrm{p}<0.001$. ${ }^{*}$ By service users (i.e., excluding those with zero contact); contact counts were derived from items with seven labelled response alternatives (ranging from 'None', '1-2 times', to ' $13+$ times'), which were assigned weights of $0,2,4,6,9,12$, and 18 contacts respectively.

(35.6\%); whereas among those with unmet needs a mixture of reasons were endorsed for preferring self-management.

\section{Cross-sectional correlates of help-seeking for $\mathrm{MH}$ problems} The goal of the major multivariate analyses was to examine relationships between potential facilitators/barriers and self-reported contacts for $\mathrm{MH}$ problems, after taking into account the contributions of sociodemographic characteristics and predicted service needs based on recent health status indicators (e.g., symptoms/ distress, adverse experiences). A series of hierarchical logistic regressions was conducted for the outcome variables of professional and non-professional service utilisation during the last 12 months, each coded as no contact (0) versus any contact (1). Socio-demographic characteristics were entered simultaneously at step 1 (see Table 4), followed by the 11 predictors listed in Table 5 at step 2 .

As detailed in Table 4, higher rates of contact with professionals were reported by females (20\% vs. $13 \%$, $\mathrm{AOR}=1.64, p=.004)$ and those in poorer financial circumstances ( $24 \%$ vs. $13 \%, \mathrm{AOR}=2.17, p=.003)$; while higher rates of contacts with non-professionals were also reported by females ( $19 \%$ vs. $10 \%$, AOR $=2.14, p<.001)$,

Table 3 Perceived barriers and self-management profiles for selected sub-groups reporting MH problems in the last 12 months

\begin{tabular}{|c|c|c|c|}
\hline \multirow{2}{*}{$\begin{array}{l}\text { Barriers to adequate health care: } \\
\text { Factor (Potential score range: } 1-5 \text { ) }\end{array}$} & \multicolumn{2}{|c|}{ Self-reported MH problems in last 12 months } & \multirow{2}{*}{$\begin{array}{l}\text { Statistical } \\
\text { comparisons } \\
\text { ( } p \text {-values) }\end{array}$} \\
\hline & $\begin{array}{l}\text { Help/advice not } \\
\text { sought }(N=143)\end{array}$ & $\begin{array}{l}\text { Help/advice sought-Needs } \\
\text { not met }(\mathrm{N}=75)\end{array}$ & \\
\hline & Mean (SD) & & \\
\hline Structural barriers to help-seeking & $1.38(0.68)$ & $2.15(1.19)$ & ** \\
\hline Attitudinal barriers to help-seeking & $2.30(0.76)$ & $2.38(0.95)$ & .834 \\
\hline Time commitments & $1.35(0.64)$ & $1.67(0.95)$ & .027 \\
\hline \multirow[t]{2}{*}{$\begin{array}{l}\text { Self-management reasons: (Main reason for } \\
\text { preferring to manage problems themselves) }\end{array}$} & $(\mathrm{N}=104)$ & $(N=40)$ & \\
\hline & $\%$ Endorsement & & \\
\hline "I don't think they know how to help" & 12.5 & 25.0 & $* *(d f=5)$ \\
\hline "I'm uncomfortable talking about these problems" & 35.6 & 15.0 & \\
\hline "I rely on faith and spirituality" & 6.7 & 7.5 & \\
\hline "I rely on family and friends" & 35.6 & 20.0 & \\
\hline "I'd be treated differently if people thought I had a mental illness" & 2.9 & 17.5 & \\
\hline "I don't think it is fair to expect it" & 6.7 & 15.0 & \\
\hline
\end{tabular}

Note: Other sub-groups were not asked to complete the barriers questions; statistical comparisons were based on ANCOVAs (for continuous variables), controlling for socio-demographic characteristics (using 15 dummy coded variables representing the categories detailed in Table 4), or overall chi-square tests (for categorical variables): ${ }^{*} \mathrm{p}<0.01 ;{ }^{* *} \mathrm{p}<0.001$. 
Table 4 Relationships between socio-demographic characteristics and reported professional and non-professional contacts for MH problems-ARMHS 3-year follow-up ( $\mathrm{N}=1231)$

\begin{tabular}{|c|c|c|c|c|c|}
\hline \multirow[t]{2}{*}{ Socio-demographic characteristic ${ }^{*}$} & \multirow[t]{2}{*}{ Sub-group $\mathbf{N}$} & \multicolumn{2}{|c|}{ Professional service utilisation } & \multicolumn{2}{|c|}{ Non-professional service utilisation } \\
\hline & & $\mathrm{N}(\%)$ & AOR $(99 \% \mathrm{Cl})$ & $\mathrm{N}(\%)$ & AOR $(99 \% \mathrm{Cl})$ \\
\hline \multicolumn{6}{|l|}{ Age (years): } \\
\hline $18-34$ & 52 & $10(19)$ & & $10(19)$ & \\
\hline $35-44$ & 124 & $31(25)$ & $1.74(0.58,5.19)$ & $30(24)$ & $1.54(0.51,4.62)$ \\
\hline $45-54$ & 266 & $60(23)$ & $1.51(0.54,4.24)$ & $59(22)$ & $1.34(0.48,3.76)$ \\
\hline $55-64$ & 379 & $63(17)$ & $1.10(0.39,3.11)$ & $55(15)$ & $0.86(0.30,2.45)$ \\
\hline $65+$ & 410 & $52(13)$ & $0.75(0.26,2.20)$ & $40(9.8)$ & $0.57(0.19,1.71)$ \\
\hline \multicolumn{6}{|l|}{ Gender: } \\
\hline Male & 478 & $63(13)$ & & $48(10)$ & \\
\hline Female & 753 & $153(20)$ & $1.64(1.06,2.55)^{*}$ & $146(19)$ & $2.14(1.32,3.45)^{* *}$ \\
\hline \multicolumn{6}{|l|}{ Education: } \\
\hline Partial schooling & 303 & $40(13)$ & & $32(11)$ & \\
\hline Completed high school or above & 857 & $160(19)$ & $1.63(0.95,2.77)$ & $152(18)$ & $1.86(1.04,3.33)^{*}$ \\
\hline Unknown & 71 & $16(23)$ & $2.04(0.85,4.93)$ & $10(14)$ & $1.50(0.53,4.23)$ \\
\hline \multicolumn{6}{|l|}{ Marital status: } \\
\hline Married/de facto & 950 & $145(15)$ & & $130(14)$ & \\
\hline Divorced/separated & 121 & $31(26)$ & $1.67(0.91,3.08)$ & $35(29)$ & $2.41(1.31,4.43)^{* *}$ \\
\hline Widowed & 90 & $19(21)$ & $1.91(0.87,4.19)$ & $13(14)$ & $1.50(0.62,3.68)$ \\
\hline Never married & 70 & $21(30)$ & $2.09(0.97,4.49)$ & $16(23)$ & $1.62(0.71,3.73)$ \\
\hline \multicolumn{6}{|l|}{ ASGC category (Remoteness): } \\
\hline Inner regional & 544 & $98(18)$ & & $89(16)$ & \\
\hline Outer regional & 419 & $70(17)$ & $0.91(0.57,1.43)$ & $63(15)$ & $0.92(0.57,1.49)$ \\
\hline Remote & 179 & $29(16)$ & $0.77(0.41,1.43)$ & $23(13)$ & $0.67(0.34,1.33)$ \\
\hline Very remote & 89 & $19(21)$ & $1.13(0.54,2.40)$ & $19(21)$ & $1.36(0.63,2.93)$ \\
\hline \multicolumn{6}{|l|}{ Financial position: } \\
\hline Prosperous/comfortable & 198 & $26(13)$ & & $28(14)$ & \\
\hline Reasonable & 671 & $104(16)$ & $1.30(0.70,2.42)$ & $91(14)$ & $0.99(0.54,1.84)$ \\
\hline Just getting along to very poor & 362 & $86(24)$ & $2.17(1.12,4.18)^{*}$ & $75(21)$ & $1.67(0.86,3.23)$ \\
\hline
\end{tabular}

Note: Based on a series of hierarchical logistic regressions, in which socio-demographic characteristics were entered simultaneously at step 1, followed by potential facilitators/barriers at step 2 (see Table 5): ${ }^{*} \mathrm{p}<0.01 ;{ }^{* *} \mathrm{p}<0.001$. ARMHS: Australian Rural Mental Health Study; AOR: Adjusted Odds Ratio; Cl: Confidence Interval. ${ }^{¥}$ Comparable categories to Table 3 of Perkins et al. (2013) [24], but based on 3-year follow-up data.

those who completed high school or above (18\% vs. $11 \%$, $\mathrm{AOR}=1.86, p=.006)$, and divorced/separated individuals (29\% vs. $14 \%, \mathrm{AOR}=2.41, p<.001)$. Geographical remoteness was not associated with professional or nonprofessional help-seeking.

Four of the predictors showed consistent patterns of association with both professional and non-professional help-seeking (see Table 5). As expected, there was essentially a dose-response relationship between predicted service need and the likelihood of using services, with a three-fold increase in the likelihood of any service contact (AORs of 3.29 and 3.23, $p<.001$ ) for those with a medium PSNI score, and over a twelve-fold increase (AORs of 14.00 and 12.32, $p<.001$ ) for those with a high PSNI score. Although statistically non-significant, recent suicidal ideation (AORs of 2.41, $p=.037$, and $2.68, p=.016)$ was consistently associated with a higher likelihood of service use (over and above the influences captured in the PSNI), as was preparedness to use the internet for $\mathrm{MH}$ treatment/information (AORs of 3.13 and 3.03, $p<.001)$. Conversely, after controlling for the other associations, higher endorsement of attitudinal barriers (by those to whom these questions were addressed) was associated with a substantial reduction in the likelihood of seeking any help, either professional or non-professional (AORs of 0.10 and $0.15, p<.001$ ).

Two additional statistically significant associations with professional service usage were detected. Firstly, higher 
Table 5 Relationships between potential facilitators/barriers and reported professional and non-professional contacts for MH problems-ARMHS 3-year follow-up

\begin{tabular}{|c|c|c|c|c|c|}
\hline \multirow[t]{2}{*}{ Characteristic } & \multirow{2}{*}{$\begin{array}{l}\text { Sub-group } \\
\mathrm{N}\end{array}$} & \multicolumn{2}{|c|}{ Professional service utilisation } & \multicolumn{2}{|c|}{ Non-professional service utilisation } \\
\hline & & $\mathrm{N}(\%)$ & AOR $(99 \% \mathrm{Cl})$ & $\mathrm{N}(\%)$ & AOR $(99 \% \mathrm{Cl})$ \\
\hline \multicolumn{6}{|l|}{ Employment status: } \\
\hline Not currently employed & 531 & $98(19)$ & & $75(14)$ & \\
\hline Employed or volunteer work & 700 & $118(17)$ & $0.83(0.47,1.46)$ & $119(17)$ & $1.23(0.68,2.20)$ \\
\hline \multicolumn{6}{|l|}{ Children in house: } \\
\hline No & 922 & $152(17)$ & & $136(15)$ & \\
\hline Yes & 309 & $64(21)$ & $0.76(0.38,1.49)$ & $58(19)$ & $0.56(0.27,1.13)$ \\
\hline \multicolumn{6}{|l|}{ Caring for family member/friend: } \\
\hline No & 1102 & $186(17)$ & & $169(15)$ & \\
\hline Yes & 129 & $30(23)$ & $0.94(0.44,2.05)$ & $25(19)$ & $0.88(0.41,1.93)$ \\
\hline \multicolumn{6}{|l|}{ Predicted Service Need Index (PSNI): } \\
\hline Low $(0-1)$ & 819 & $73(8.9)$ & & $66(8.1)$ & \\
\hline Medium (2-5) & 297 & $76(26)$ & $3.29(1.94,5.56)^{* *}$ & $69(23)$ & $3.23(1.87,5.59)^{* *}$ \\
\hline High $(>5)$ & 115 & $67(58)$ & $14.00(6.24,31.4)^{* *}$ & $59(51)$ & $12.32(5.55,27.3)^{* *}$ \\
\hline \multicolumn{6}{|l|}{ Suicidal ideation (PHQ-9, item 9): } \\
\hline No & 1187 & $189(16)$ & & $172(15)$ & \\
\hline Yes (present in last two-weeks) & 44 & $27(61)$ & $2.41(0.81,7.13)$ & $22(50)$ & $2.68(0.94,7.70)$ \\
\hline \multicolumn{6}{|l|}{ Easy access to internet: } \\
\hline No & 290 & $50(17)$ & & $39(13)$ & \\
\hline Yes & 941 & $166(18)$ & $0.91(0.48,1.73)$ & $155(17)$ & $0.85(0.43,1.66)$ \\
\hline \multicolumn{6}{|l|}{ Would use internet for MH treatment/information: } \\
\hline No & 859 & $103(12)$ & & $87(10)$ & \\
\hline Yes & 372 & $113(30)$ & $3.13(1.85,5.29)^{* *}$ & $107(29)$ & $3.03(1.78,5.17)^{* *}$ \\
\hline \multicolumn{6}{|l|}{ Continuous variables (dummy coded) ${ }^{*}$} \\
\hline Structural barriers to help-seeking & (Range: 1-5) & & $2.30(1.20,4.44)^{* *}$ & & $0.88(0.53,1.47)$ \\
\hline Attitudinal barriers to help-seeking & (Range: $1-5$ ) & & $0.10(0.05,0.22)^{* *}$ & & $0.15(0.08,0.29)^{* *}$ \\
\hline Time commitments & (Range: 1-5 ) & & $1.12(0.56,2.25)$ & & $1.11(0.58,2.15)$ \\
\hline Number of contacts with other service type & (Range: 0-42) & & $0.93(0.87,0.99)^{*}$ & $(0-126)$ & $0.98(0.95,1.01)$ \\
\hline
\end{tabular}

Note: Based on a series of hierarchical logistic regressions, in which socio-demographic characteristics were entered simultaneously at step 1 (see Table 4), followed by the current set of predictors at step 2: ${ }^{*} p<0.01$; ${ }^{* *} p<0.001$. ARMHS: Australian Rural Mental Health Study; AOR: Adjusted Odds Ratio; Cl: Confidence Interval. ${ }^{\ddagger}$ Dummy coding was used for these variables (i.e., allocating mean scores to those with "missing" data) as they only applied to selected sub-groups, namely those who answered the barriers section of the survey (i.e., MH problems but no advice sought, or needs not met) and those with at least one service contact (for the "number of contacts" variable).

endorsement of structural barriers was associated with an increased likelihood of reporting professional contacts (AOR of 2.30, $p<.001$ ). Secondly, there was a tendency for (each unit of) increased contacts with non-professionals to reduce the likelihood of accessing professional help (AOR of $0.93, p=.003$ ).

Finally, to better understand relationships between predicted service needs, barriers and the overall number of contacts for $\mathrm{MH}$ problems in the last 12 months $(\mathrm{N}=394)$, we plotted mean contact patterns for selected subgroups (see Figure 1). These sub-groups were selected for illustrative purposes, based on the key predictors identified in the major regression analyses (Table 5); it should also be noted that, where appropriate, those who did not seek advice are included in these sub-groups (with zero service usage), as they also identified potential barriers. Three broad patterns are evident: increased service need (PSNI) is clearly associated with increased contacts for all sub-groups; individuals reporting their needs were met had the highest overall contact rates; and 'barriers' are likely to be associated with a mixed pattern of help-seeking-potentially impacting differentially on the likelihood of seeing someone and the number of contacts by those who actually sought help. 


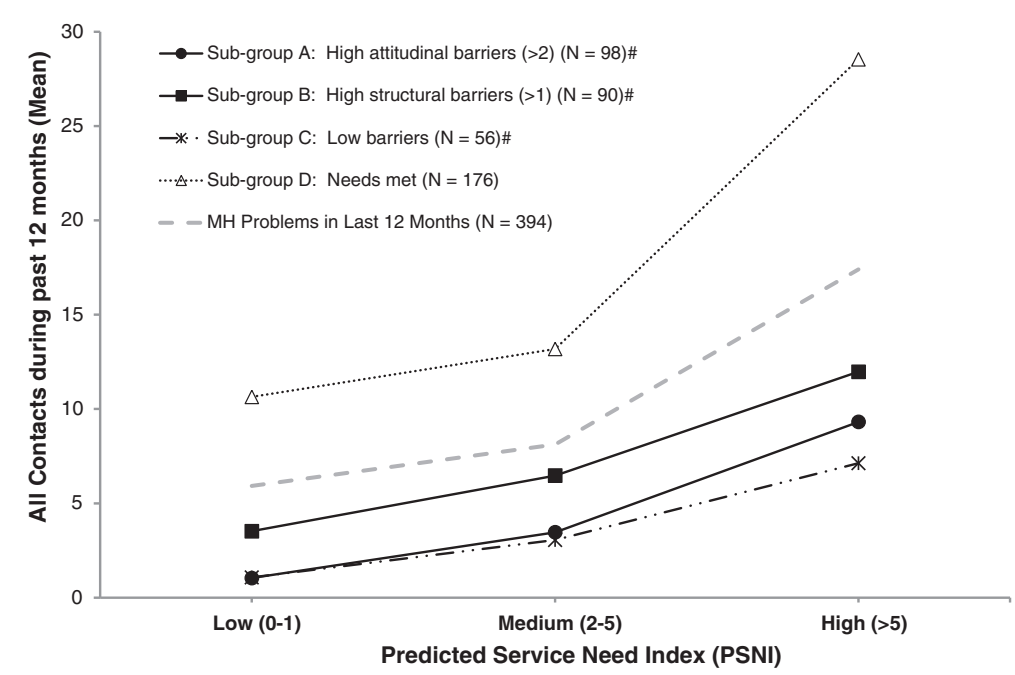

Figure 1 Self-reported contacts by individuals reporting mental health problems during the past 12 months: selected subgroups by predicted service need. (\# Among those asked the barriers questions-i.e., advice not sought, or needs not met).

\section{Discussion}

\section{Brief summary of selected findings}

This brief summary is provided, to help frame subsequent discussion:

1) one-third (32.0\%) of the total sample self-reported $\mathrm{MH}$ problems in the last 12 months, amongst whom one-third (36.3\%) did not seek any help and onefifth $(19.0 \%)$ indicated their needs were not met;

2) overall help-seeking rates were similar to baseline findings (professionals: $17.5 \%$ vs. $17.3 \%$; nonprofessionals: $15.6 \%$ vs. $11.6 \%$ ) [24], rising to approximately half of the sub-group in the highest need category (professionals: 58.3\%; non-professionals: 51.3\%);

3) observed help-seeking rates and the dose-response relationship between predicted service needs (indicative of the severity of current problems) and the likelihood of using services were also broadly consistent with national survey findings in Australia [25] and elsewhere [23]; and

4) attitudinal barriers were consistently associated with a lower likelihood of help seeking, even after socio-demographic factors, predicted service needs, and structural barriers were taken into account.

\section{Unravelling needs, help-seeking and barriers}

Interestingly, few characteristics distinguished between participants who did and did not seek help, or those who reported receiving enough help. While females were more likely to seek help, they were also over-represented among those with unmet needs. Financial difficulties were also more marked among those reporting unmet needs, a common finding in many studies [34,35], while conversely employed participants with $\mathrm{MH}$ problems were less likely to seek help. PSNI scores were higher among help-seekers, and highest in the group who did not feel they had received enough help; however, participants who had received enough help may have initially had higher PSNI scores, but these reduced as a result of effective assistance. Notwithstanding, severity was highest among people who were unable to access sufficient help (despite attempts to do so), which is reflective of the importance of providing accessible and acceptable services in rural areas.

As indicated by our principal component analysis, perceived barriers to mental health care fell under the domains of structural (e.g., costs, distance), attitudinal (e.g., stigma concerns, confidentiality), and time commitments. At first glance, the barriers-related findings in Table 4 and Figure 1 appear somewhat inconsistent; however, the logistic regressions examined predictors of the likelihood of seeking any professional or non-professional help, while Figure 1 details the mean number of contacts by those reporting $\mathrm{MH}$ problems. The most parsimonious explanation is that barriers play a mixture of roles (and/or come in a variety of forms, complicating their measurement). For example, attitudinal barriers may contribute both to a lower likelihood of seeking any help (e.g., privacy concerns, or limited possibilities) and to lower contact rates even when help is initially sought (e.g., self-management preferences). On the other hand, the identification of structural barriers may arise within the context of helpseeking (e.g., high costs or transport issues), by those with current needs (and, in the current study, poorer financial circumstances), and contribute to a lower number of contacts than considered desirable or optimal-resulting in self-reported unmet needs. Additionally, other factors, 
such as rural stoicism, could contribute both to not seeking help and to the non-identification of barriers. It should also be acknowledged that higher self-management preferences should not be automatically viewed negatively, since many associated strategies (e.g., reducing substance use, increasing participation and physical activity) are endorsed by the community as a positive influence on mental health [36].

The present study did not seek to examine or disentangle the potential drivers of current $\mathrm{MH}$ problems and/or barriers to care, but rather to assess their contributions to professional and non-professional help-seeking. However, public health or other interventions designed to improve or optimise the provision of $\mathrm{MH}$ care should ideally target factors that both reduce the need for care and minimise potential barriers for those seeking help. Three factors from our study that appear to have relevance to each of these are relationships (support networks), financial difficulties and stigma. For example, being married was associated with a lower likelihood of experiencing $\mathrm{MH}$ problems (reinforcing our earlier findings [37]), and with lower help-seeking, while recent financial problems was associated with higher rates of both. Attitudinal factors, including perceived stigma, can also contribute to higher distress and lower help seeking. Likewise, interventions that seek to reduce suicidal ideation and behaviours and/ or increase associated help-seeking can impact on overall $\mathrm{MH}$ care profiles.

That attempting to seek help is an important contributor to the recognition of structural barriers concords with recent research demonstrating structural barriers are identified more as severity increases [23]. Structural barriers may not stop rural residents from seeking help initially, however, they do impact on their ability to receive an adequate level of care; and, more generally, they impact on treatment drop-out [23]. Perhaps not surprisingly, structural barriers did not have a significant association with non-professional help-seeking, indicating that challenges to accessing services may not influence rural residents' desire or ability to receive some assistance; likewise, geographical remoteness did not differentially affect help-seeking. On the other hand, attitudinal barriers reduce the likelihood of help-seeking substantially.

\section{Study limitations}

The present study has several limitations, including under-representation of younger adults and reliance on self-reported $\mathrm{MH}$ data; the target group for the barriers questions could have also been expanded to include those who reported their needs were met. Perceived barriers may also vary across cultures [38], MH problems and treatment providers [39], and possibly with increasing comorbidity, although this has yet to be established [34]; none of which were assessed in the current study.
The broader health service context within which the ARMHS project was conducted also sets some limits on international comparisons, since Australia has a centralised health system, with subsidised access to General Practitioners and medical specialists. Conversely, the study also has considerable strengths, such as community (as opposed to service) based recruitment, high representation of participants from remote/very remote regions, and applicability of our findings to rural areas. While the current study focussed on mental health problems, it may also be the case that older adults in rural areas experience a constellation of barriers to health care [35], almost regardless of the nature of their problems.

\section{Conclusions}

This paper explored cross-sectional associations between predicted service needs, perceived barriers, and professional and non-professional help-seeking by rural and remote residents in NSW, Australia. Previous research has shown that rural residents may have a preference for informal help-seeking and consider professional service use as a last resort [15]. However, our findings about attitudinal barriers apply to both professional and nonprofessional help-seeking. The implications of this may be considerable in relation to the initiation of public health interventions and optimising rural $\mathrm{MH}$ service use. In recent years, there has been an emphasis on increasing the provision of services through innovative strategies, such as internet-delivered treatments [40] and information [20], telehealth facilities, and attempts to attract more $\mathrm{MH}$ professionals to rural and remote areas of Australia [41]. However, targeting issues related to physical availability alone may not be sufficient to adequately increase service use by rural and remote residents. In addition, although internet-delivered treatments may increase service contacts by current help-seekers, they may not necessarily increasing overall help-seeking.

Participants with recent suicidal ideation were generally more likely to report help-seeking in the past 12 months, however, the relevant sample sizes were small and, within the context of the multivariate analyses, these effects were not statistically significant. Research indicates that a contributor to elevated rural suicide rates may be the lower help-seeking behaviour in non-metropolitan areas [42]. The present findings do not indicate a lack of desire for help; moreover, among a younger sample rates of and barriers to formal service use for those experiencing suicidal thoughts may have been different.

Preparedness to use the internet was higher among those reporting $\mathrm{MH}$ problems and other service contacts, which is consistent with earlier findings [26,43]. However, while internet-delivered treatments may eventually improve rural residents' access to $\mathrm{MH}$ resources [20], at present they are subject to many of the same barriers as traditional 
MH services. Addressing perceptions of mental illness and attitudes towards help-seeking, through the development and evaluation of appropriate interventions, is likely to be vital in improving and optimising service use and $\mathrm{MH}$ outcomes in rural and remote Australia.

\section{Additional file}

Additional file 1: Table S1. Relationships between current health status characteristics and reported professional contacts for $\mathrm{MH}$ problems - ARMHS baseline and 3-year follow-up. Table S2. Relationships between current health status characteristics and reported non-professional contacts for MH problems - ARMHS baseline and 3-year follow-up. Table S3. Perceived barriers and self-management profiles for selected sub-groups reporting $\mathrm{MH}$ problems in the last 12 months. Table S4. Relationships between sociodemographic characteristics and reported professional and non-professional contacts for MH problems - ARMHS 3-year follow-up ( $N=1231)$.

\section{Abbreviations}

ADSL: Asymmetric digital subscriber line; ANCOVA: Analysis of covariance; ANOVA: Analysis of variance; AOR: Adjusted odds ratio; ARMHS: Australian rural mental health study; AUDIT: Alcohol use disorders identification test; ASGC: Australian standard geographic classification; Cl: Confidence Interval; GP: General practitioner; K10: Kessler-10 measure of current psychological distress; MH: Mental health; PHQ-9: Patient Health Questionnaire-9; PSNI: Predicted (Provisional) service need index; SD: Standard deviation.

\section{Competing interests}

The authors declare that they have no competing interests.

\section{Authors' contributions}

BJK had the original idea for the ARMHS project and is the lead investigator, while TJL, JF, and DP are also chief investigators. TEH, FKL and KJ initiated the current component of the study, and TEH drafted the manuscript. CC co-ordinated data collection and management, and together with TIL, TEH, and NW contributed to the analysis and generation of results. All authors provided interpretation of the findings and contributed to manuscript preparation and revision. All authors read and approved the final manuscript.

\section{Acknowledgements}

We wish to recognise the contribution of the other ARMHS chief investigators: David Lyle, Lyn Fragar, John Beard, Vaughan Carr, Helen Stain, and Prasuna Reddy. The study was funded by the National Health and Medical Research Council (Project Grants \#401241 and \#631061) and also supported by a Research Capacity Building Grant to the Australian Rural Health Research Collaboration. We wish to acknowledge the support of Area Directors of Mental Health Services during the course of this phase of the study: Russell Roberts, Richard Buss, Dinesh Arya and particularly acknowledge the research site coordinators in each site: Jan Sidford, John Ogle (Broken Hill), Trim Munro, Amy Strachan (Moree), Louise Holdsworth, Kath O'Driscoll (Lismore), Cheryl Bennett, Jannelle Bowler (Orange), along with Fleur Hourihan, Gina Sartore, Denika Novello and the team of CIDI interviewers. Tonelle Handley would like to acknowledge Australian Rotary Health/Rotary Club of Parramatta City for their support through the provision of a PhD scholarship.

\footnotetext{
Author details

${ }^{1}$ Centre for Translational Neuroscience and Mental Health, University of Newcastle and Hunter New England Health, Callaghan, NSW, Australia. ${ }^{2}$ Centre for Rural and Remote Mental Health, University of Newcastle, Orange, NSW, Australia. ${ }^{3}$ National Drug and Alcohol Research Centre, University of New South Wales, Sydney, NSW, Australia. ${ }^{4}$ Hunter Medical Research Institute, Locked Bag 1, Hunter Region Mail Centre, Newcastle, NSW, Australia. ${ }^{5}$ Centre for Clinical Epidemiology and Biostatistics, University of Newcastle and Hunter New England Health, Newcastle, NSW, Australia. ${ }^{6}$ School of Nursing and Midwifery, Flinders University, Adelaide, SA, Australia.
}

Received: 7 March 2014 Accepted: 22 August 2014

Published online: 06 September 2014

\section{References}

1. Gamm L, Hutchison L: Rural health priorities in America: where you stand depends on where you sit. J Rural Health 2003, 19:209-213.

2. Kessler RC, Barker PR, Colpe L, Epstein JF, Gfroerer JC, Hiripi E, Howes MJ, Normand SLT, Manderscheid RW, Walters EE, Zaslavsky AM: Screening for serious mental illness in the general population. Arch Gen Psychiatry 2003, 60:184-189.

3. Goldney RD, Taylor AW, Bain MA: Depression and remoteness from health services in South Australia. Aust J Rural Health 2007, 15:201-210.

4. Smith KB, Humphreys JS, Wilson MGA: Addressing the health disadvantage of rural populations: how does epidemiological evidence inform rural health policies and research? Aust J Rural Health 2008, 16:56-66.

5. Fraser C, Judd F, Jackson H, Murray G, Humphreys J, Hodgins GA: Does one size really fit all? Why the mental health of rural Australians requires further research. Aust J Rural Health 2002, 10:288-295.

6. Caldwell TM, Jorm AF, Knox S, Braddock D, Dear KBG, Britt H: General practice encounters for psychological problems in rural, remote and metropolitan areas in Australia. Aust N Z J Psychiatry 2004, 38:774-780.

7. Judd FK, Humphreys JS: Mental health issues for rural and remote Australia. Aust J Rural Health 2001, 9:254-258.

8. Fortney J, Rost $\mathrm{K}$, Zhang ML, Warren J: The impact of geographic accessibility on the intensity and quality of depression treatment. Med Care 1999, 37:884-893.

9. Hartley D, Korsen N, Bird D, Agger M: Management of patients with depression by rural primary care practitioners. Arch Fam Med 1998, 7:139-145.

10. Zulian G, Donisi V, Secco G, Pertile R, Tansella M, Amaddeo F: How are caseload and service utilisation of psychiatric services influenced by distance? A geographical approach to the study of community-based mental health services. Soc Psychiatry Psychiatr Epidemiol 2011, 46:881-891.

11. Judd F, Jackson H, Komiti A, Murray G, Fraser C, Grieve A, Gomez R: Helpseeking by rural residents for mental health problems: the importance of agrarian values. Aust N Z J Psychiatry 2006, 40:769-776.

12. Fuller J, Edwards J, Procter N, Moss J: How definition of mental health problems can influence help seeking in rural and remote communities. Aust J Rural Health 2000, 8:148-153.

13. Wrigley S, Jackson $H$, Judd F, Komiti A: Role of stigma and attitudes toward help-seeking from a general practitioner for mental health problems in a rural town. Aust N Z J Psychiatry 2005, 39:514-521.

14. Hussain R, Guppy M, Robertson S, Temple E: Physical and mental health perspectives of first year undergraduate rural university students. BMC Public Health 2013, 13:848.

15. Komiti $A$, Judd $F$, Jackson $H$ : The influence of stigma and attitudes on seeking help from a GP for mental health problems. Soc Psychiatry Psychiatr Epidemiol 2006, 41:738-745.

16. Booth ML, Bernard D, Quine S, Kang MS, Usherwood T, Alperstein G, Bennett DL: Access to health care among Australian adolescents: young people's perspectives and their sociodemographic distribution. J Adoles Health 2004, 34:97-103.

17. Griffiths $\mathrm{K}$, Christensen $\mathrm{H}$, Jorm $\mathrm{A}$ : Mental health literacy as a function of remoteness of residence: an Australian national study. BMC Public Health 2009, 9:1-20.

18. Rost K, Smith R, Tayler J: Rural-urban differences in stigma and the use of care for depressive disorders. J Rural Health 1993, 9:57-62.

19. AlHW: Rural, Regional and Remote Health: Indicators of Health. Canberra: Australian Institute of Health and Welfare; 2005.

20. Ruggiero K, Gros DF, McCauley J, de Arellano MA, Danielson CK: Rural adults' use of health-related information online: data from a 2006 National Online Health Survey. Telemed e-Health 2011, 17:329-334.

21. Sareen J, Jagdeo A, Cox BJ, Clara I, ten Have M, Belik SL, de Graaf R, Stein MB: Perceived barriers to mental health service utilization in the United States, Ontario, and the Netherlands. Psychiatr Sen 2007, 58:357-364.

22. Urbanoski KA, Cairney J, Bassani DG, Rush BR: Perceived unmet need for mental health care for Canadians with co-occurring mental and substance use disorders. Psychiatr Serv 2008, 59:283-289.

23. Mojtabai R, Olfson M, Sampson NA, Jin R, Druss B, Wang PS, Wells KB, Pincus $H A$, Kessler RC: Barriers to mental health treatment: results from the National Comorbidity Survey Replication. Psychol Med 2011, 41:1751-1761.

24. Perkins D, Fuller J, Kelly BJ, Lewin TJ, Fitzgerald M, Coleman C, Inder KJ Allan J, Arya D, Roberts R, Buss R: Factors associated with reported service use for mental health problems by residents of rural and remote 
communities: cross-sectional findings from a baseline survey. BMC Health Serv Res 2013, 13:157.

25. Burgess PM, Pirkis JE, Slade TN, Johnston AK, Meadows GN, Gunn JM: Service use for mental health problems: findings from the 2007 National Survey of Mental Health and Wellbeing. Aust N Z J Psychiatry 2009, 43:615-623.

26. Handley TE, Kay-Lambkin FJ, Inder KJ, Attia JR, Lewin TJ, Kelly BJ: Feasibility of internet-delivered mental health treatments for rural populations. Soc Psychiatry Psychiatr Epidemiol 2014, 49:275-282.

27. Kelly BJ, Stain HJ, Coleman C, Perkins D, Fragar L, Fuller J, Lewin TJ, Lyle D, Carr VJ, Wilson JM, Beard JR: Mental health and well-being within rural communities: the Australian Rural Mental Health Study. Aust J Rural Health 2010, 18:16-24.

28. Kelly BJ, Lewin TJ, Stain HJ, Coleman C, Fitzgerald M, Perkins D, Carr VJ, Fragar L, Fuller J, Lyle D, Beard JR: Determinants of mental health and well-being within rural and remote communities. Soc Psychiatry Psychiatr Epidemiol 2011, 46:1331-1342.

29. Wooden M, Freidin S, Watson N: The Household, Income and Labour Dynamics in Australia (HILDA) survey: wave 1. Aust Econ Rev 2002, 35:339-348.

30. Andrews $\mathrm{G}$, Slade T: Interpreting scores on the Kessler psychological distress scale (K10). Aust N Z J Pub Health 2001, 25:494-497.

31. Saunders JB, Aasland OG, Babor TF, de la Fuente JR, Grant M: Development of the Alcohol Use Disorders Identification Test (AUDIT): WHO collaborative project on early detection of persons with harmful alcohol consumption-II. Addiction 1993, 88:791-804.

32. Conigrave KM, Hall WD, Saunders JB: The AUDIT questionnaire: choosing a cut-off score. Addiction 1995, 90:1349-1356.

33. Kroenke K, Spitzer RL, Williams JB: The PHQ-9: validity of a brief depression severity measure. J Gen Intern Med 2001, 16:606-613.

34. Chen LY, Crum RM, Martins SS, Kaufmann CN, Strain EC, Mojtabai R: Service use and barriers to mental health care among adults with major depression and comorbid substance dependence. Psychiatr Serv 2013, 64:863-870.

35. Thorpe J, Thorpe C, Kennelty K, Pandhi N: Patterns of perceived barriers to medical care in older adults: a latent class analysis. BMC Health Serv Res 2011, 11:181.

36. Olesen SC, Butterworth P, Leach L: Prevalence of self-management versus formal service use for common mental disorders in Australia: findings from the 2007 National Survey of Mental Health and Wellbeing. Aust N Z J Psychiatry 2010, 44:823-830.

37. Allen J, Inder K, Lewin T, Attia J, Kelly B: Social support and age influence distress outcomes differentially across urban, regional and remote Australia: an exploratory study. BMC Public Health 2012, 12:928.

38. Kido Y, Kawakami N: Sociodemographic determinants of attitudinal barriers in the use of mental health services in Japan: findings from the World Mental Health Japan Survey 2002-2006. Psychiatry Clin Neurosci 2013, 67:101-109.

39. Yap MBH, Reavley N, Jorm AF: Where would young people seek help for mental disorders and what stops them? Findings from an Australian national survey. J Affect Disord 2013, 147:255-261.

40. Griffiths KM, Christensen H: Internet-based mental health programs: a powerful tool in the rural medical kit. Aust J Rural Health 2007, 15:81-87.

41. Conomos AM, Griffin B, Baunin N: Attracting psychologists to practice in rural Australia: the role of work values and perceptions of the rural work environment. Aust J Rural Health 2013, 21:105-111.

42. Taylor R, Page A, Morrell S, Harrison J, Carter G: Social and psychiatric influences on urban-rural differentials in Australian suicide. Suicide Life Threat Behav 2005, 35:277-290.

43. Pohjanoksa-Mäntylä M, Bell JS, Helakorpi S, Närhi U, Pelkonen A, Airaksinen M: Is the internet replacing health professionals? A population survey on sources of medicines information among people with mental disorders. Soc Psychiatry Psychiatr Epidemiol 2011, 46:373-379.

doi:10.1186/s12888-014-0249-0

Cite this article as: Handley et al:: Self-reported contacts for mental health problems by rural residents: predicted service needs, facilitators and barriers. BMC Psychiatry 2014 14:249.

\section{Submit your next manuscript to BioMed Central and take full advantage of:}

- Convenient online submission

- Thorough peer review

- No space constraints or color figure charges

- Immediate publication on acceptance

- Inclusion in PubMed, CAS, Scopus and Google Scholar

- Research which is freely available for redistribution

Submit your manuscript at www.biomedcentral.com/submit 